\title{
Aerosol and rainfall variability over the Indian monsoon region: distributions, trends and coupling
}

\author{
R. Gautam ${ }^{1,2}$, N. C. Hsu' ${ }^{2}$, K.-M. Lau $^{2}$, and M. Kafatos ${ }^{3}$ \\ ${ }^{1}$ Goddard Earth Science and Technology Center, University of Maryland Baltimore County, Baltimore, MD 21228, USA \\ ${ }^{2}$ Laboratory for Atmospheres, NASA Goddard Space Flight Center, Greenbelt, MD 20771, USA \\ ${ }^{3}$ Center of Excellence in Earth Observing, Schmid College of Science, Chapman University, Orange, CA 92866, USA
}

Received: 30 March 2009 - Revised: 23 July 2009 - Accepted: 7 September 2009 - Published: 30 September 2009

\begin{abstract}
Aerosol solar absorption over the Indian monsoon region has a potential role of modulating the monsoon circulation and rainfall distribution as suggested by recent studies based on model simulations. Prior to the onset of the monsoon, northern India is influenced by significant dust transport that constitutes the bulk of the regional aerosol loading over the Gangetic-Himalayan region. In this paper, a multi-sensor characterization of the increasing premonsoon aerosol loading over northern India, in terms of their spatial, temporal and vertical distribution is presented. Aerosol transport from the northwestern arid regions into the Indo-Gangetic Plains and over the foothills of the Himalayas is found to be vertically extended to elevated altitudes (up to $5 \mathrm{~km}$ ) as observed from the space-borne lidar measurements (CALIPSO). In relation with the enhanced pre-monsoon aerosol loading and the associated solar absorption effects on tropospheric temperature anomalies, this paper investigates the monsoon rainfall variability over India in recent past decades from an observational viewpoint. It is found that the early summer monsoon rainfall over India is on the rise since 1950s, as indicated by historical rainfall data, with over 20\% increase for the period 1950-2004. This large sustained increase in the early summer rainfall is led by the observed strengthening of the pre-monsoon tropospheric land-sea thermal gradient over the Indian monsoon region as indicated by microwave satellite measurements (MSU) of tropospheric temperatures from 1979-2007. Combined analysis of changes in tropospheric temperatures and summer monsoon rainfall in the past three decades, suggest a future possibility of an emerging rainfall pattern of a wetter monsoon over South Asia in early summer followed by a drier period.
\end{abstract}

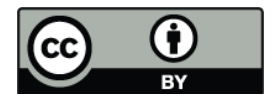

Correspondence to: R. Gautam (ritesh.gautam@nasa.gov)
Keywords. Atmospheric composition and structure (Aerosols and particles; Pollution - urban and regional) Meteorology and atmospheric dynamics (Precipitation)

\section{Introduction}

A growing body of evidence indicates that tropospheric aerosols, a major component of the global climate system, significantly influence the Earth's radiation budget and climate forcing. The multi-faceted impacts on climate coupled with the considerable lack of observations of their properties and spatio-temporal distribution makes aerosols one of the least understood components of the Earth's climate (IPCC, 2007, and several references therein). Over heavily polluted and populated regions, the difficulty in quantifying aerosol effects is exacerbated. For example over Asia, observations from extensive field campaigns have indicated strong effects of aerosols on the Earth's radiation budget and on regional climate. In the past decade or so, several field campaigns such as the Indian Ocean Experiment (INDOEX), Aerosol characterization experiment (ACE) Asia, East Asian Studies of Tropospheric Aerosols: An International Regional Experiment (EAST-AIRE), with a suite of state-of-the-art instruments, have been conducted in order to assess the direct and indirect effects of aerosols on the regional climate, radiation and monsoon rainfall (Ramanathan et al., 1998; Huebert et al., 2001; Li et al., 2007). The South Asian region, in general, and the Indo-Gangetic Plains (IGP), in particular, where about $1 / 6$ th of the world's population live is one of the major hotspots of increasing atmospheric pollution due to rapid urbanization/industrialization and growing energy demands. Bounded by the high-altitude Himalayas in the north, the region's climate is largely governed by the summer (southwest) and winter (northeast) monsoons.

Published by Copernicus Publications on behalf of the European Geosciences Union. 
The INDOEX field campaign was particularly successful in recognizing the importance of aerosols over the surrounding oceanic regions off the subcontinent. Prior to the INDOEX, several studies of aerosol characterization in the form of field experiments have also been conducted in southern India as part of the Indian Space Research Organization (ISRO) Indian Middle Atmosphere Program (Krishnamoorthy et al., 1999; Sikka, 2002). However, over northern India, specifically in the IGP, the importance of aerosols and their various climatic effects have been little known despite the heavy pollution in the region. Moreover, the Gangetic plains are densely populated with about 600 million people relying on the various hydrological and agricultural resources. With the aid of satellite data, several studies have recently mapped the extent and magnitude of the aerosol loading over IGP. The more common aerosol loading indicator, i.e. Aerosol Optical Depth (AOD), has been used in several studies to elucidate the high pollution levels in the region (Massie et al., 2004; Girolamo et al., 2004; Prasad et al., 2004). The detailed characterization of seasonal aerosol loading over single location in IGP, Kanpur $\left(26.45^{\circ} \mathrm{N}, 80.34^{\circ} \mathrm{E}\right)$, has been documented (Singh et al., 2004) which has been made possible through NASA's AERONET program (Holben et al., 1998). In general, a large sustained increasing aerosol loading trend has been found over northern India in the IGP with the analysis of NASA TOMS data in the past two decades (Massie et al., 2004; Habib et al., 2006; Sarkar et al., 2007; Bollasina et al., 2008).

In this paper, we focus our study on the pre-monsoon season when the regional aerosol loading is strongly influenced by the transport of dust outbreaks originating in the Thar Desert in northwestern India and in the Arabian Peninsula. Dust storms over India are major synoptic events and due to the valley-type regional topography, dust particulates accumulate largely over the IGP and significantly influence the aerosol optical properties (Dey et al., 2004; Singh et al., 2004; El-Askary et al., 2006; Prasad and Singh, 2007; Gautam et al., 2009a) as well as the regional radiation budget (Singh et al., 2005; Prasad et al., 2007; Pandithurai et al., 2008). The importance of dust solar absorption has been recognized as a potential forcing in altering rainfall distribution globally (Miller et al., 2004) and more specifically over South Asia (Lau et al., 2006a ,b). With the growing attention on the potential effects of aerosol radiative forcing on the Indian monsoon rainfall and circulation in recent years (Menon et al., 2002; Ramanathan et al., 2005; Lau et al., 2006; Meehl et al., 2008), here we analyze the pre-monsoon aerosol loading and the monsoon rainfall variability from long-term observations over India.

\section{Data}

Inter-annual variability of aerosol loading is studied from the Aerosol Index (AI) dataset obtained from the Nimbus 7 and
Earth Probe Total Ozone Mapping Spectrometer (TOMS) satellite measurements for the period 1979-1992 and 19972001, respectively. The TOMS AI dataset is the longest record for studying the spatial and temporal variability of aerosols on regional and global scales. It has been highly successful in detecting absorbing aerosols particularly over desert regions which have demonstrated the feasibility and success of the TOMS AI dataset (Hsu et al., 1999; Prospero et al., 2002). We use the most recent version released to date, i.e. version-8 AI dataset (Wellemeyer et al., 2004; Ahmad et al., 2006). Although, TOMS AI data are available till 2005, however due to calibration issues associated with sensor degradation, trend analysis of the data after 2001 is not recommended as per the NASA TOMS science team (http://daac.gsfc.nasa.gov/guides/GSFC/guide/ tomsl3_dataset.gd.shtml) and other available documentation (Kiss et al., 2007; Bollasina et al., 2008). Hence, we restrict the trend analysis of AI data till 2001. In addition to the Nimbus 7 and Earth Probe TOMS data, AI is also obtained from the Ozone Monitoring Instrument (OMI) aboard NASA's Aura satellite. The OMI AI dataset is also derived using the version-8 TOMS methodology and is consistent in its derivation using same wavelength channel with respect to TOMS (Ahmad et al., 2006; Li et al., 2009). More details about the consistency between the TOMS and OMI retrievals are given in Sect. 4.

We also use aerosol loading information from the space borne Moderate Resolution Imaging Spectroradiometer (MODIS) instrument over both vegetated as well as arid regions (Hsu et al., 2004; Levy et al., 2007). Aerosol vertical distribution information is obtained from the CloudAerosol Lidar with Orthogonal Polarization (CALIOP) instrument that provides global vertically-resolved measurements of aerosol and clouds in the atmosphere (Winker et al., 2003). The CALIOP can observe aerosol over bright surfaces and beneath thin clouds as well as in clear sky conditions. We use the Level 1B data that contains a half orbit (day or night) of calibrated and geo-located single-shot (highest resolution) lidar profiles, including $532 \mathrm{~nm}$ and $1064 \mathrm{~nm}$ attenuated backscatter and depolarization ratio at $532 \mathrm{~nm}$. The vertical resolution for both the profile specific and fixed altitude arrays is $30 \mathrm{~m}$.

Long-term rainfall data over India are obtained from the Indian regional/sub divisional Monthly Rainfall data set generated by the Indian Meteorological Department. This dataset is available from 1871 to 2004 from a network of rain-gauges which consist of 306 almost uniformly distributed stations for which rainfall data are available from 1871 (Parthasarathy et al., 1995). Further details of the long-term data are provided at: http://iridl.ldeo.columbia.edu/SOURCES/.IITM/ .All_India/.Rainfall/.dataset_documentation.html. In addition to the long-term rainfall data from gauge stations, we also analyze the spatially-homogeneous rainfall dataset from the Global Precipitation Climatology Project (GPCP) that 


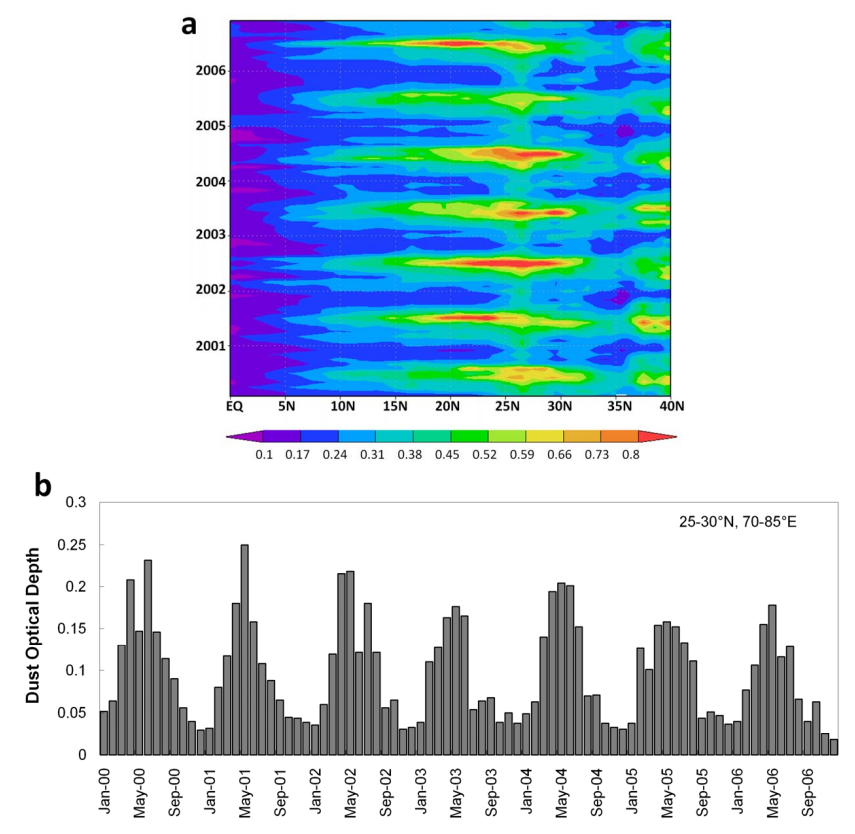

Fig. 1. (a) Inter-annual variability of MODIS AOD over India (zonal mean: $60-100^{\circ} \mathrm{E}$ ) from 2001 to 2006 ; the AOD peaks during the pre-monsoon season and, (b) dust optical depth from GOCART model outputs over northern India region $\left(25-30^{\circ} \mathrm{N}, 70-85^{\circ} \mathrm{E}\right)$.

combines satellite and gauge measurements. The Version 2 satellite-gauge precipitation estimates were obtained from 1979 to present on a 2.5 degree grid spatial resolution. These data were obtained from http://ingrid.ldeo.columbia. edu/SOURCES/.NASA/.GPCP/.V2/.

\section{Aerosol scenario over the Gangetic-Himalayan region}

\subsection{Inter-annual variability}

Aerosols over the IGP undergo strong seasonality in terms of the loading as well as aerosol type (Singh et al., 2004; Jethva et al., 2005; Lau et al., 2008). During spring and summer seasons, dust aerosols are transported from the northwestern arid regions to the IGP (Middleton, 1986; Prospero et al., 2002). On the other hand, fine-mode pollution particles such as soot and sulfate form the bulk of the regional atmospheric loading resulting in dense haze and foggy conditions during winter months (Girolamo et al., 2004; Prasad et al., 2006; Gautam et al., 2007). Heavy dust loading results in maximum column AOD during pre-monsoon period, while contribution of fine mode pollution aerosols to the total optical depth, such as sulfate and soot, is highest during the post-monsoon and winter period. Figure 1a shows the inter-annual variability of monthly mean AOD over the entire Indian subcontinent (eq- $40^{\circ} \mathrm{N}, 60-100^{\circ} \mathrm{E}$ ) (zonal mean) for the period 2001-2006. As indicated by MODIS observa- tions, higher AOD persists in the pre-monsoon season over India which is most pronounced over northern India (20$30^{\circ} \mathrm{N}$ ), associated with the enhanced dust transport into the IGP. The maximum dust influx from the northwestern arid region peaks during May which is also suggested by high dust optical depths (Fig. 1b) from aerosol transport model outputs (Goddard Global Ozone Chemistry Aerosol Radiation Transport, or GOCART, see Chin et al., 2002).

\subsection{Spatial distribution}

The aerosol transport and loading over this region is strongly governed by the background prevailing meteorology. Dust transport, driven by pre-monsoon westerlies, is clearly mapped by MODIS observations (see Fig. 2: mean AOD for the pre-monsoon period 2003-2006; Gautam et al., 2009b). Not only are the plains influenced with heavy aerosol loading, but due to enhanced convection, aerosols are vertically advected to elevated altitudes as well $(>3 \mathrm{~km})$ against the foothills of the Himalayas as seen in the climatological mean AOD (Fig. 2). With the onset of rainy season (the Arabian Sea and Bay of Bengal branches of the southwest summer monsoon), the heavy dust loading significantly diminishes due to aerosol washout from the atmosphere. While the summer monsoon is an intense large-scale synoptic phenomenon characterized by heavy rainfall, the northeast monsoon during winter months (also referred to as the retreat of the monsoon) accounts for very little rainfall associated with light winds from the subcontinent towards the ocean and marks the beginning of dry season in India. Ground-based measurements from sunphotometer deployed at Kanpur in central IGP, part of the AERONET, have indicated significant seasonal variations in particle size in different seasons (Singh et al., 2004).

The spatial extent of the dust-laden regions is also clearly visible in Fig. 3 which represents the climatological mean of TOMS AI for May and June from 1979 to 2001 with a gap of satellite data availability (1993-1996). The desert regions of Pakistan, Afghanistan, Iran and Thar Desert in Northwestern India as well as the dust-transported regions such as the IGP exhibit significantly high aerosol index (greater than 2). Long-range transport of dust from the Arabian Peninsula over the northern Arabian Sea also results in high values of AI. The spatial extent of aerosol loading over the northern Arabian Sea appears to be higher in June due to the strong monsoon wind-blown dust aerosols. Another dustladen hotspot is the Taklimakan desert, north of the Tibetan Plateau, which is one of the major sources of dust emissions in the atmosphere and significantly affects the air quality and climate over China (Xuan and Sokolik, 2002).

The aerosol loading in the South Asian regions also show large spatial gradients associated with differences in topography. For example, in contrast to the IGP, the foothills of Himalayas and the Tibetan Plateau show significantly less aerosol burden. Similarly, large spatial differences in AI are 


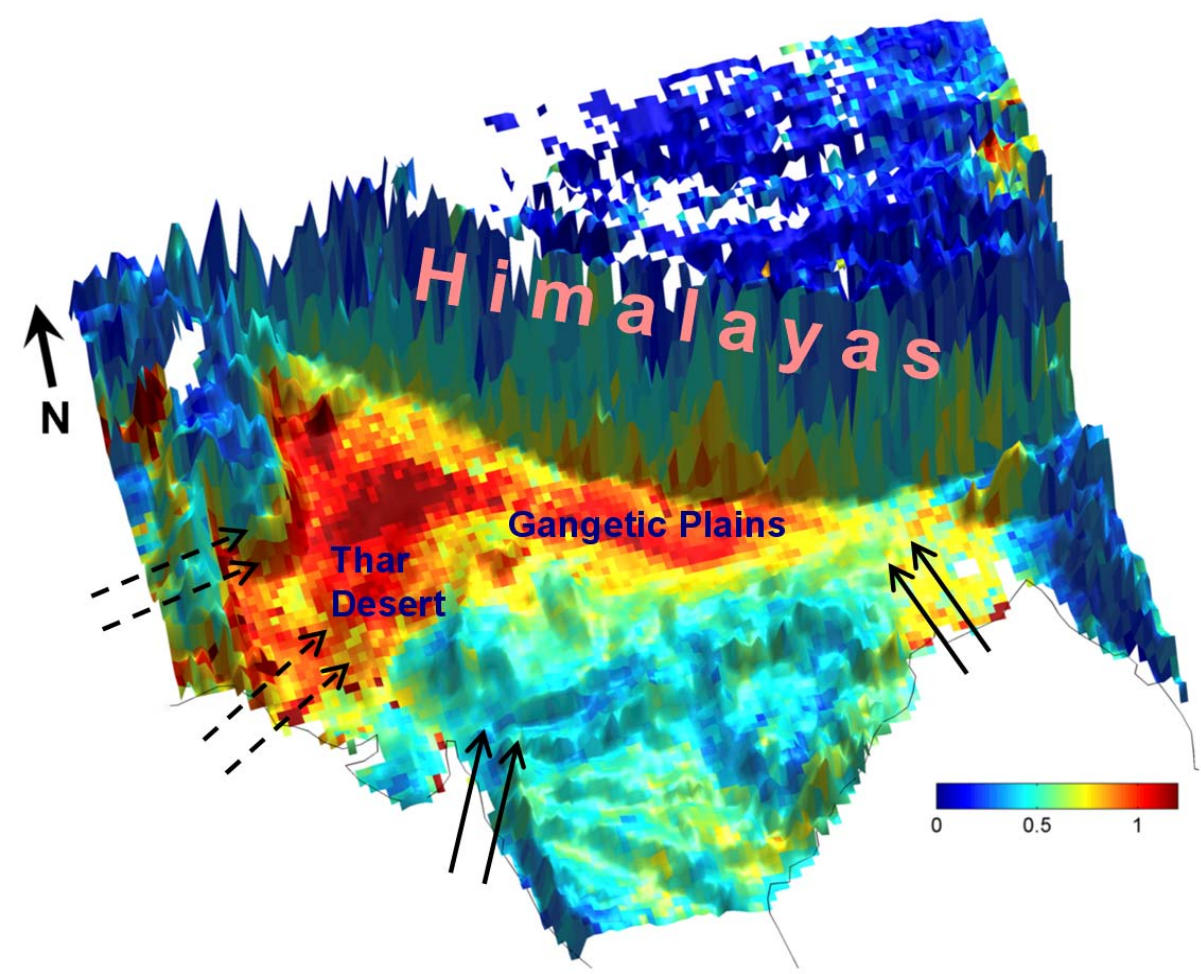

Fig. 2. Climatological mean of Aerosol Optical Depth during pre-monsoon season overlaid onto the surface topography (from Gautam et al., 2009b). Passage of dust transport is clearly visible from the western desert/arid regions into the alluvium of the IGP. Dashed arrows indicate pre-monsoon westerlies and black arrows indicate the passage of moisture transport from Arabian Sea/Indian Ocean into southern India and from Bay of Bengal into the eastern parts of the subcontinent during monsoon season.

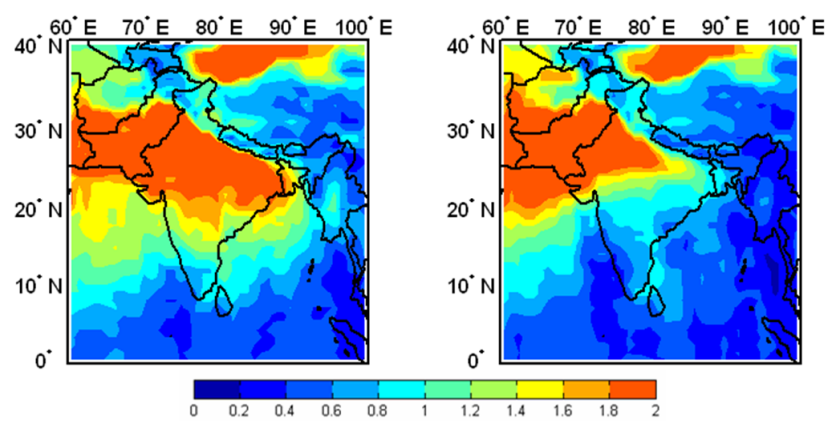

Fig. 3. TOMS Aerosol Index Climatology for May (left) and June (right).

observed over the Hindu Kush Mountains and the desert regions to the South. Over northern India, in contrast to the high aerosol loading over western IGP and the Thar Desert, the eastern IGP in comparison is associated with significantly low AI values. According to the onset dates of the summer monsoon, reported by the Indian Meteorological Department, the eastern IGP receives rainfall earlier compared to western regions. The Bay of Bengal branch of south-west monsoon brings rainfall to regions in the southern slopes of Eastern Himalayas as early as in the first week of June. It is also a widely held fact that the cumulative monsoon rainfall is highest in the North-East regions in the Indian subcontinent. The excess rainfall in the first half of June may be responsible for the aerosol washout resulting in decrease in the total column loading of natural or anthropogenic particles and hence the drop in AI.

\subsection{Aerosol vertical distribution}

While the aerosol solar extinction from MODIS and TOMS is a valuable indicator of the aerosol loading, it only provides information of the total atmospheric column. For more accurate knowledge of aerosol-induced climate perturbations, vertical distribution of aerosols is required. CALIOP is a space-borne lidar, launched in 2006, which provides global vertical distribution of aerosols and clouds. Figure $4 \mathrm{a}$ shows the nighttime depolarization ratio profile (derived from backscatter measurements) in May transecting across the Thar Desert, over the IGP, and the HimalayasTibetan Plateau on 12 May 2007. During pre-monsoon and summer months, due to enhanced convection, aerosols are lofted to elevated altitudes in the troposphere. Together with the westerly pre-monsoon winds, enhanced convection and the steep pressure gradient across the Himalayan-Gangetic region steer aerosols aloft which results in higher backscatter 

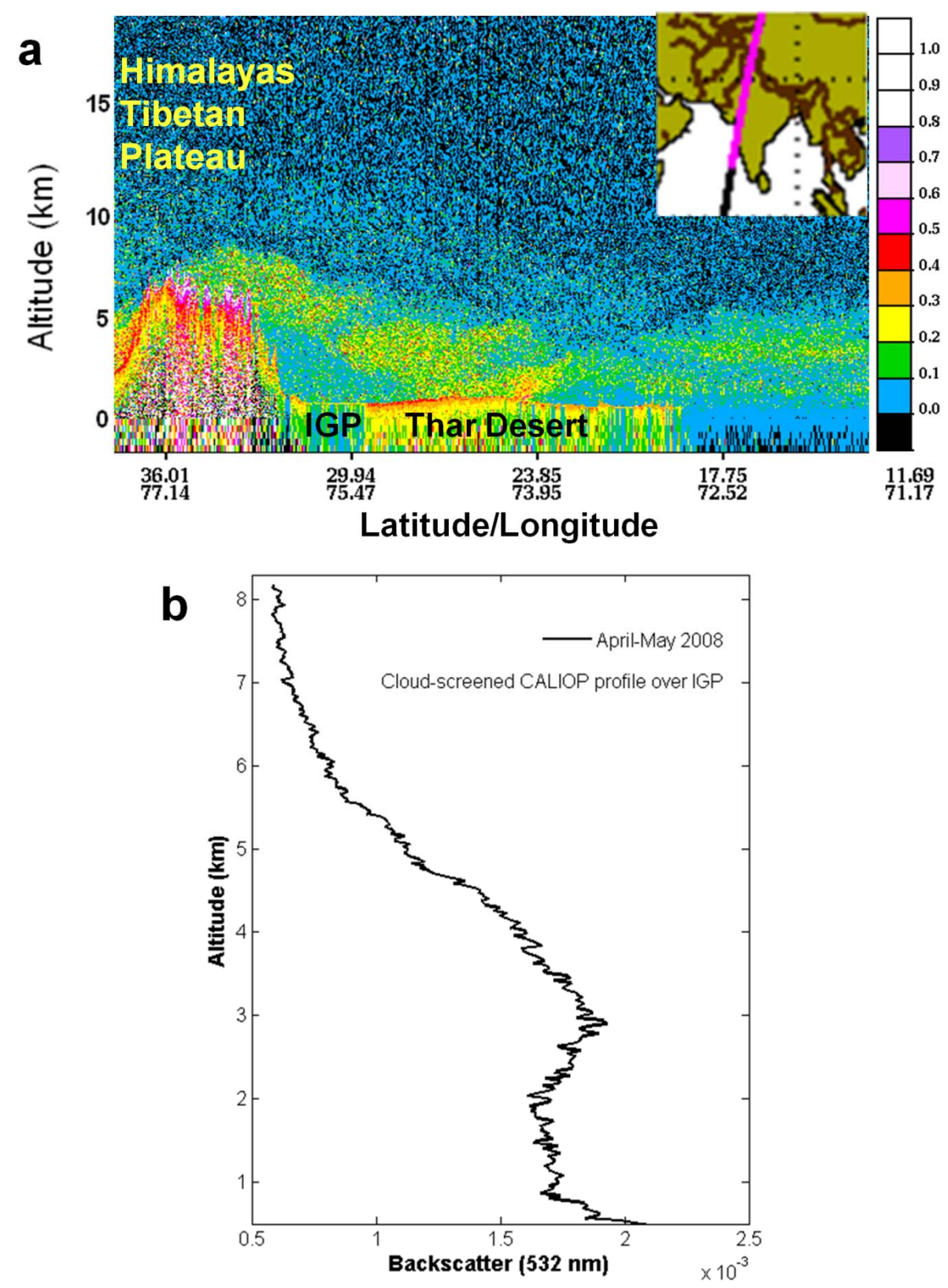

Fig. 4. (a) Depolarization ratio profile across the Thar Desert and over the Gangetic-Himalayan region, and (b) mean cloud-screened CALIOP backscatter profile for April-May 2008 over IGP.

due to aerosols at elevated altitudes $(\sim 5 \mathrm{~km})$. The depolarization ratio indicates the type of particles and is a good proxy to distinguish between spherical (such as sulfate) and non-spherical (such as dust) aerosols. It is defined as the ratio of the perpendicular and parallel components of the attenuated backscatter signal (Liu et al., 2008). Higher depolarization suggests the presence of large concentrations of dust or non-spherical particles in the layer in cloud-free conditions. Gautam et al. (2009a) used the depolarization ratio extensively over the Indian subcontinent to infer the contribution of dust during pre-monsoon season and separate that with other anthropogenic emissions in this region.

Higher depolarization ratio values over the Thar Desert $\left(\sim 25^{\circ} \mathrm{N}\right.$ in the lidar transect, Fig. $\left.4 \mathrm{a}\right)$ is an indication of the desert dust lifting associated with the near-surface aerosols. The elevated dust transport $(3-5 \mathrm{~km})$ over the plains $(29-$ $30^{\circ} \mathrm{N}$ ), i.e. north of the desert region in the lidar transect, is associated with higher depolarization ratio values $(0.2-$ $0.3)$ compared to the significantly lower values $(<0.1)$ in the boundary layer most likely associated with fine-mode 
spherical particles resulting from anthropogenic pollution. This sharp contrast in the depolarization ratio, across the vertical cross-section in Fig. 4a, appears to be more pronounced due to the relatively stable atmosphere during nighttime. It should be noted though that the high depolarization ratio observed over the Himalayas-Tibetan Plateau and the southern slopes $\left(32-36^{\circ} \mathrm{N}\right.$ along the transect) are possibly associated with cloud attenuation, most likely due to the presence of ice crystals, which are also non-spherical in shape. Thus, the feature over the Himalayas should not be interpreted as aerosol layer as also indicated by the CALIPSO vertical feature mask (not shown).

We analyzed CALIPSO Level-1b attenuated backscatter profiles over the IGP during April-May 2008. An essential pre-processing step to analyze aerosol vertical distribution is to cloud-screen the profiles. The Level-2 cloud-layer product was utilized to filter out cloud contamination in the backscatter profiles, where cloud top and bottom are reported for each cloud layer found in a single vertical profile. Backscatter profiles for April-May 2008 were averaged to a 5-km horizontal resolution (15 lidar shot averaging) in order to make those consistent with the $5-\mathrm{km}$ resolution cloud-layer product to screen the signal due to the attenuation by clouds. The resulting cloud-free backscatter profiles over a selected region in the IGP $\left(25-27^{\circ} \mathrm{N}, 80-85^{\circ} \mathrm{E}\right)$ were averaged to represent the mean vertical distribution of aerosols. Figure $4 \mathrm{~b}$ shows the mean backscatter profile over the IGP where the aerosol transport is characterized by large attenuation associated with dust particles (most likely mixed with heavy local pollution) at elevated altitudes peaking around $3 \mathrm{~km}$ and extends up to $5 \mathrm{~km}$. The knowledge of aerosol vertical extent is important as it influences radiative heating rates and may influence the stability of the atmosphere. Over northern India and the foothills of the Himalayas, enhanced aerosol radiative heating may potentially strengthen the monsoon circulation by atmospheric-driven feedbacks (Lau et al., 2006). The following section discusses the role of aerosol solar absorption and its possible influence on the Indian summer monsoon rainfall variability in connection with the tropospheric warming associated with the aerosol forcing over northern India.

\section{Aerosol and monsoon rainfall variability over India}

\subsection{Potential role of aerosols in altering rainfall distribution}

Of the greatest importance to large populations and to the poor, the Indian summer monsoon is the biggest source of freshwater resource. More than $70 \%$ of the annual precipitation over India occurs during the summer monsoon season (June-July-August-September) (Parthasarathy and Mooley, 1978; Dash et al., 2009). The subcontinent heats rapidly during the pre-monsoon months, while the Indian Ocean warm- ing is relatively less compared to the landmass. The resulting meridional thermal contrast (latitudinal gradient across the Indian landmass and the northern Indian Ocean, i.e. from equator to $40^{\circ} \mathrm{N}$ ) causes strong moisture-laden winds from the oceanic regions to the landmass leading to heavy rainfall during the monsoon period.

Against the backdrop of increasing aerosol concentrations, recent studies have recognized the potential role of aerosols inducing changes in the monsoon circulation and rainfall over India. There are two major approaches in the recent literature that demonstrate these aerosol effects as documented in Lau et al. (2008).

\subsubsection{Surface dimming effect}

This mechanism proposed by Ramanathan et al. (2005) focuses on the northern Indian Ocean region where thick haze, consisting of dust, BC, sulfate, fly ash aerosols (referred to as Atmospheric Brown Clouds), is transported from South Asia towards the India Ocean. It has been shown by Satheesh and Ramanathan (2000) that the widespread haze causes significant perturbations in the regional radiation budget with large reductions in the solar insolation at the ocean surface. The reduction of sunlight cuts the evaporation rates which further suppress convection from the ocean surface leading to reduced moisture transport towards the subcontinent during the peak monsoon season. This mechanism suggests the weakening of monsoon circulation and reduction of monsoon rainfall with the future possibility of frequent droughts.

\subsubsection{Elevated Heat Pump (EHP) hypothesis}

Lau et al. (2006a) proposed the EHP mechanism which rests on the heavy aerosol loading over northern India, primarily the IGP and over the foothills of the Himalayas, prior to the onset of the monsoon. Enhanced dust loading mixed with carbonaceous soot aerosols are vertically advected to elevated altitudes and pile up against the southern slopes of the Himalayas and cause significant warming in the middle and upper troposphere. The enhanced aerosol solar absorption creates a temperature anomaly which amplifies the overturning of the meridional circulation and thus causes to draw in more moisture from the Indian Ocean. This mechanism has been hypothesized in the advancement and intensification of the early summer monsoon.

Apart from the two proposed mechanisms, a key influence of aerosols on monsoon rainfall may take place through the modification of cloud properties such as cloud albedo, effective radius, liquid water path and so on (Kaufman and Fraser, 1997; Rosenfeld et al., 2001). Hygroscopic particles, such as sulfate aerosols, act as efficient cloud condensation nuclei $(\mathrm{CCN})$, promote cloud formation and may cause enhancement in precipitation. In contrast, aerosols that are hydrophobic in nature and do not serve as good CCN, such as soot and dust, may act to suppress rainfall. However, such short-term 
aerosol indirect effects are more likely to come into play during the rainy period and are also dependent on the prevailing meteorological conditions.

\subsection{TOMS aerosol index}

In relation with the potential role of aerosol solar absorption on the monsoon as discussed above, we analyze the monsoon rainfall variability in relation with increasing aerosol loading over the Indian subcontinent, particularly, dust-transport in the Gangetic-Himalayan region during pre-monsoon season. The atmospheric pollution, in general over India, has significantly increased as indicated by emission inventories (Guttikunda et al., 2003; Habib et al., 2006). The TOMS satellite measurements in the past two decades have also indicated large sustained increasing aerosol loading trend (based on AI data), particularly over the IGP (Habib et al., 2006; Sarkar et al., 2007). A significant positive trend was found in the winter AI data over northern India due to the increasing anthropogenic/industrial emissions (Massie et al., 2004), concentrated over this region, mostly consisting of fine-mode carbonaceous and sulfate aerosols. The pre-monsoon aerosol loading over northern India, associated with dust-dominant aerosol type, has also experienced an increase since late 1970s as indicated by TOMS measurements (Habib et al., 2006; Bollasina et al., 2008). Even though there exists data gaps in the TOMS AI record, above cited studies have demonstrated the feasibility of inferring the increasing aerosol loading tendency in a qualitative manner. The increasing dustiness has also been reported from other indirect studies using isotopically inferred temperatures from ice cores in the Himalayas-Tibetan Plateau (Thompson et al., 2000).

Figure 5a shows the TOMS derived absorbing aerosol index over northern India encompassing the IGP and the Thar Desert with an upward trend during the pre-monsoon season (March-April-May) for the period 1979-1990 from the Nimbus 7 platform. Due to the data gap thereafter until 1996, the Earth Probe TOMS AI variations are shown as a continuation in Fig. 5a. The TOMS data beyond 1990 (from Nimbus 7) and 2001 (from Earth Probe) are not used in this study due to calibration issues associated with sensor degradation (as discussed in Sect. 2). In addition, the spatial distribution from the Nimbus 7 and Earth Probe TOMS indicates a strong positive pre-monsoon aerosol loading trend over the Thar Desert with enhanced dust-transport activity into the IGP (Gautam et al., 2009b). Figure 5a also includes the pre-monsoon AI variations obtained from the Ozone Monitoring Instrument (OMI) data from 2005 to 2008.

As previously discussed in Sect. 2 about the consistency between the TOMS and OMI retrievals, we also perform an inter-comparison of AI data from Earth Probe/TOMS and OMI sensors for the only available overlapping premonsoon period of 2005 averaged over the IGP and the Thar Desert region. The results show close agreement between the two measurements $\left(r^{2}=0.8\right.$ exceeding $99 \%$ confidence) with TOMS AI values overestimating that from OMI particularly for low aerosol loading days (Fig. 5b). The bias could be a result of the calibration issues associated with the TOMS sensor after 2001 and needs to be investigated further. Unfortunately, there is no overlapping period between Nimbus 7 and Earth Probe TOMS for which the AI data can be inter-compared. However, a recent rigorous study, by $\mathrm{Li}$ et al. (2009), on the temporal and spatial variability of AI concludes that the monthly mean Earth Probe TOMS AI and OMI annual cycles agree very well with monthly mean Nimbus 7 TOMS AI both globally and regionally, indicating that the AI product is a consistent absorbing aerosol record ( $\mathrm{Li}$ et al., 2009). The results of $\mathrm{Li}$ et al. (2009) also provide a basis for combined studies using TOMS and OMI data in future. It should also be noted that the AI greatly depends on aerosol vertical distribution and is less sensitive to nearsurface or boundary layer aerosols (Hsu et al., 1999). This aspect of altitude dependence should be less pertinent to our study which focuses on the pre-monsoon season when windblown dust aerosols prevail, as compared to other seasons especially during the winter haze period when aerosols over the IGP are trapped within the boundary layer with relatively stable atmospheric conditions. Nevertheless, using the three AI datasets here, it is not intended to quantitatively construe an increasing trend in the pre-monsoon aerosol loading from 1979 to 2008 , especially when OMI is a hyperspectral sensor as opposed to the multispectral channels in TOMS with different spectral response functions. However, the version8 TOMS and OMI retrievals of aerosols are consistent with each other in terms of the derivation of AI from same wavelengths (Ahmad et al., 2006; Li et al., 2009), thus suggesting an upward tendency of aerosol loading during this period (Fig. 5a).

\subsection{Monsoon rainfall variability}

In a recent study, we showed that the AI variability over northern India during the pre-monsoon season is strongly associated with the inter-annual variability of tropospheric temperatures, with a large sustained widespread warming trend centered over the Himalayan-Gangetic region (Gautam et al., 2009b). One of the plausible mechanisms amplifying this upward pre-monsoon temperature trend is the aerosol solar absorption by heavy absorbing aerosol buildup of dust and soot in northern India (Lau et al., 2006), as also suggested by a good degree of correlation found between the two disparate satellite-derived datasets of aerosol loading and tropospheric temperatures. The study used long-term tropospheric temperature measurements of the free troposphere from the Microwave Sounding Unit (MSU) data to show the increasing temperature trend particularly during the month of May from 1979 to 2007. Tropospheric temperatures were filtered for the stratospheric cooling influence by applying the methodology of Fu et al. (2004). 

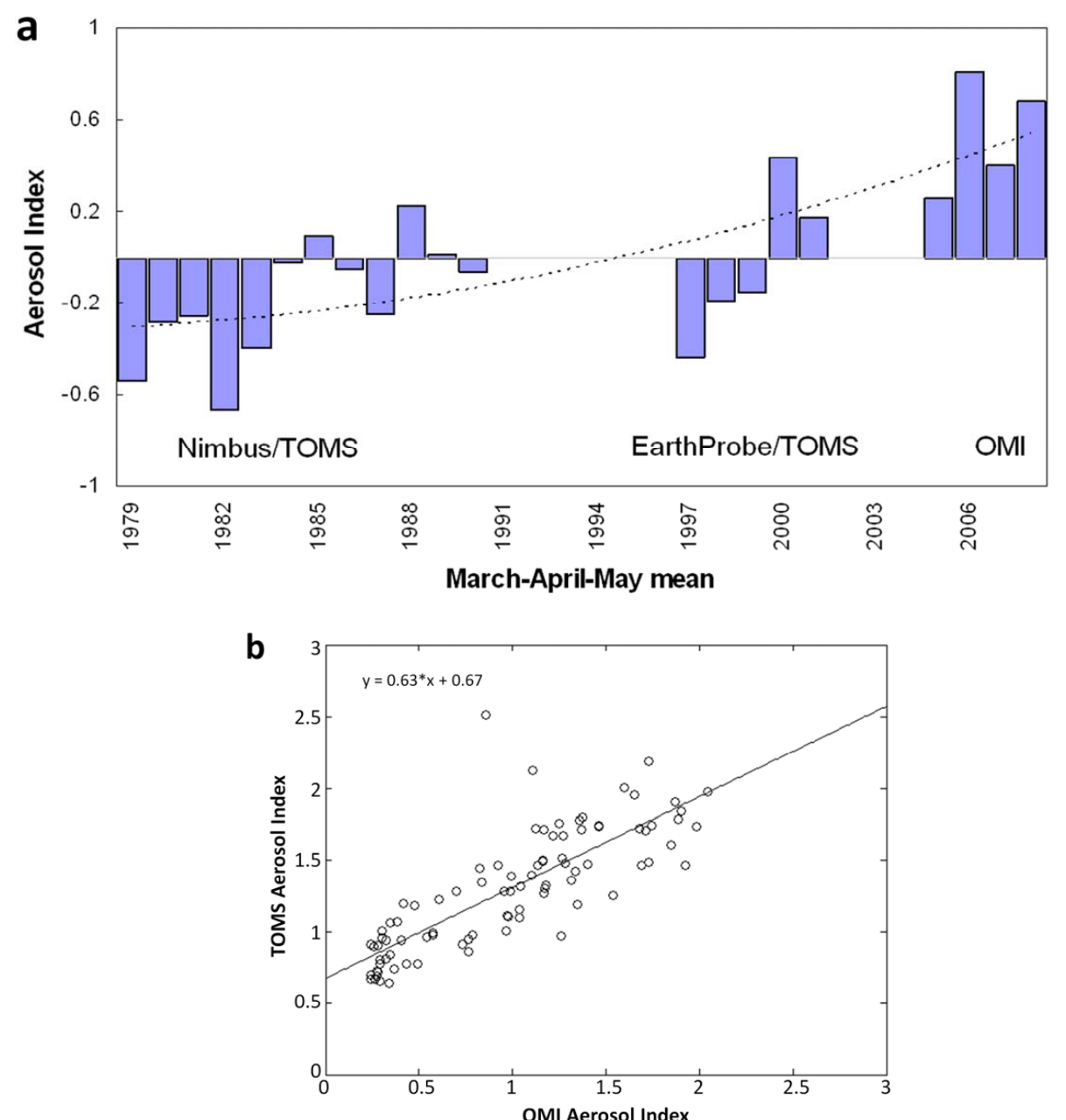

Fig. 5. (a) Inter-annual variations of pre-monsoon Absorbing Aerosol Index from Nimbus 7/TOMS (1979-1992), EarthProbe/TOMS (19972001) and OMI (2005-2008) over northern India ((25-35 $5^{\circ}$, 69-82 E), and (b) inter-comparison of AI data from Earth Probe/TOMS and OMI sensors for the only available overlapping pre-monsoon period of 2005 averaged over the IGP and the Thar Desert region.

Figure 6 shows the temperature trends for the entire pre-monsoon (March-April-May) and monsoon (June-JulyAugust) periods over the Indian Monsoon region (eq $-40^{\circ} \mathrm{N}$, $40-100^{\circ} \mathrm{E}$ ) with zonal mean temperature trend (derived from the anomaly) for the two seasons in the past three decades. As a consequence of the anomalous Himalayan tropospheric warming (Gautam et al., 2009b), there is an observed strengthening of the meridional land-sea tropospheric temperature gradient in the past three decades (Fig. 6).

Since the land-sea thermal gradient is crucial to the onset and intensity of the Indian summer monsoon, it is reasonable to anticipate that a strengthened temperature gradient may influence the monsoon rainfall, particularly the early summer rainfall. In order to investigate any influence of the observed strengthening of the pre-monsoon land-sea tropospheric temperature gradient on the monsoon rainfall variability in recent decades, we analyze the historical record of the All India Monsoon Rainfall. Here we focus on the rainfall variations in the last half century, i.e. from 1950s, that has also been the subject of recent studies (Goswami et al., 2006; Dash et al., 2009). The seasonal mean monsoon rainfall, averaged over June-July-August-September (JJAS), shows some inter-decadal variability since 1871 but lacks a significant long-term trend (Goswami et al., 2006). However, a closer look at the data, by separately analyzing individual months, reveals that the June rainfall has steadily increased in the recent past five-decade period (Fig. 7). The all India June rainfall since 1950 has increased at a rate of $0.77 \mathrm{~mm} /$ year (with 94\% confidence), which amounts to over $20 \%$ increase relative to the 1950-2004 mean June rainfall ( $\sim 161 \mathrm{~mm})$. As with the satellite tropospheric temperature data, there is an increasing trend in June rainfall over the Indian subcontinent since the late 1970s as well. In addition, spatial trend analysis of rainfall, from gauge and satellite measurements from 


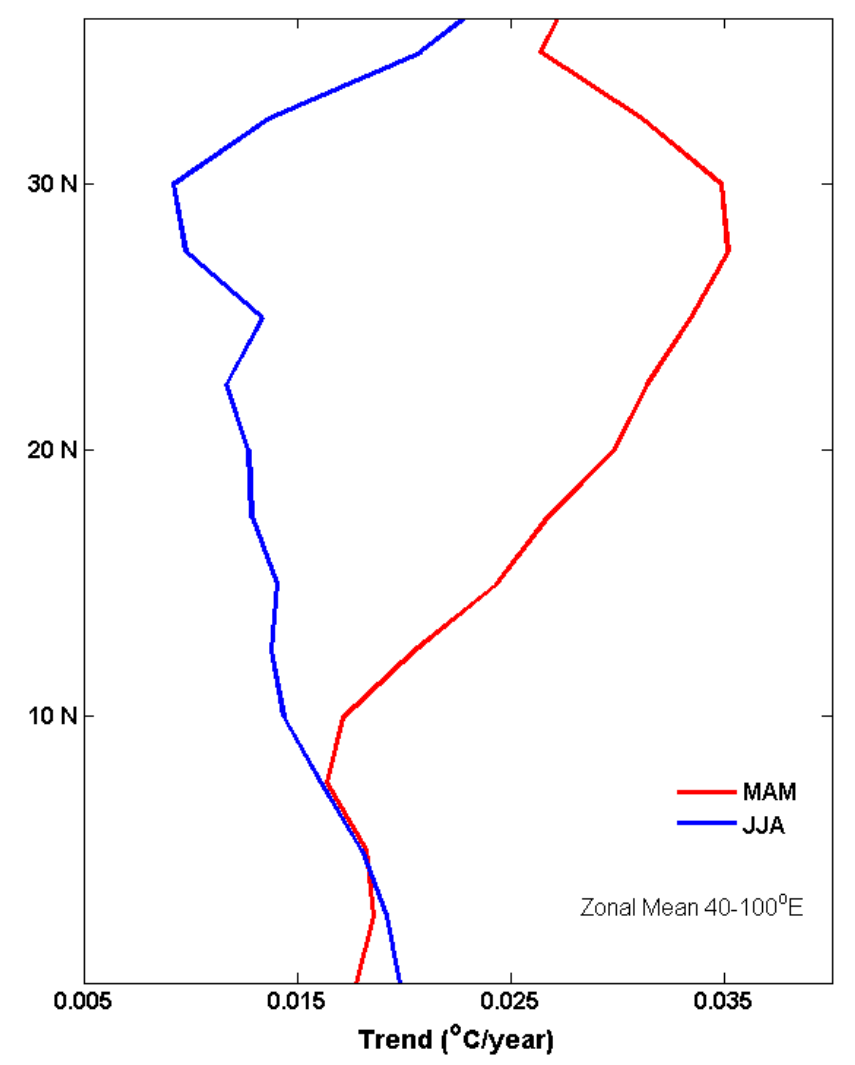

Fig. 6. Zonal mean $\left(40-100^{\circ} \mathrm{E}\right)$ latitudinal profile of midtropospheric temperature trend for the pre-monsoon season (MarchApril-May, or MAM in red) and monsoon season (June-JulyAugust, or JJA in blue) from 1979 to 2007.

GPCP, indicates strong upward trends over the Indian Monsoon region including the Arabian Sea and the Bay of Bengal (Fig. 8). The spatial rainfall pattern also resembles the characteristic large-scale rainfall pattern associated with the EHP effect (Lau and Kim, 2006).

In contrast to the steadily increasing June rainfall in recent decades, all the remaining monsoon months, from July to September, are characterized by rainfall deficit since the late 1950s (Fig. 7). Table 1 shows the trends with their significance level for each monsoon month during the longterm period 1950-2004 averaged over the entire Indian subcontinent from the IITM dataset. Apparently, as the MSU data show, the strengthened pre-monsoon land-sea temperature gradient significantly weakens during June-July-August (Fig. 6). The land-sea tropospheric temperature gradient appears to be rather stabilized with very little warming recorded over the arid regions to the west of the Himalayas as well. In fact, oceanic regions south of $10^{\circ} \mathrm{N}$ exhibit upward trends comparable to the continental regions to the north and are even higher compared to the Indian subcontinent (which is associated with weak negative-neutral trends). Following the reduced warming, the observed deficit from July to Septem-
Table 1. Trend values and their significance of monsoon rainfall over India calculated from the All-India monsoon rainfall data from IITM for June, July, August and September for the period 19502004.

\begin{tabular}{lrr}
\hline & \multicolumn{2}{c}{ 1950-2004 } \\
& Trend & Confidence \\
\hline June & 0.49 & $94 \%$ \\
July & -0.80 & $98 \%$ \\
August & -0.32 & NS \\
September & -0.53 & $91 \%$ \\
\hline
\end{tabular}

NS denotes trend not significant.

ber appears to have compensated the marked rainfall increase in June resulting in a weak weakening trend of the recent composite JJAS rainfall. Increased rainfall in the early monsoon season may lead to regional atmosphere-land feedback that cools the land surface (Bollasina et al., 2008) subsequently reducing rainfall during the peak monsoon months (July-August).

The increasing trend of June rainfall is also supported by surface observations of the strengthening of sea surface winds over the Arabian Sea during the early summer monsoon period since 1997 (Goes et al., 2005). In addition, snow cover over the Himalayas, which is another important factor governing the onset and strength of the monsoon, has been found to be declining both annually and in May as well (Goes et al., 2005). The fact that the tropospheric warming and the declining snow cover in May occur simultaneously suggests a plausible physically consistent scenario for the recent increasing trend of June rainfall. Additionally, the increasing June rainfall has also been found to be associated with an upward trend in the water vapor in northern India demonstrated by enhanced transport of moisture from the Arabian Sea (Gautam et al., 2009b). With respect to other monsoon months, it is interesting to note that, unlike characteristic decreasing trends in August and September rainfall, the July trend is greatly influenced by the large negative 2002 anomaly associated with the severe drought year. Exclusion of the anomalous year 2002 from July time series yields a weak positive trend in the July rainfall. However, the observations of increasing June rainfall, including the variability of rainfall during other months, require more detailed and extensive analysis of historical datasets, particularly finer resolution rainfall datasets (daily, 5-10 days scale) compared to the monthly analysis carried out in this paper. Moreover, the rainfall distribution over the whole of India has large spatial variations and thus a more rigorous analysis of the different homogeneous agro-climatic zones (Dash et al., 2009) is required along with other key variables that are known to affect the monsoon circulation and rainfall such as SST gradient, heat fluxes and convective instability (Shukla, 1987; Sikka, 2003; Meehl and Arblaster, 2003; Ramanathan et al., 2005), 


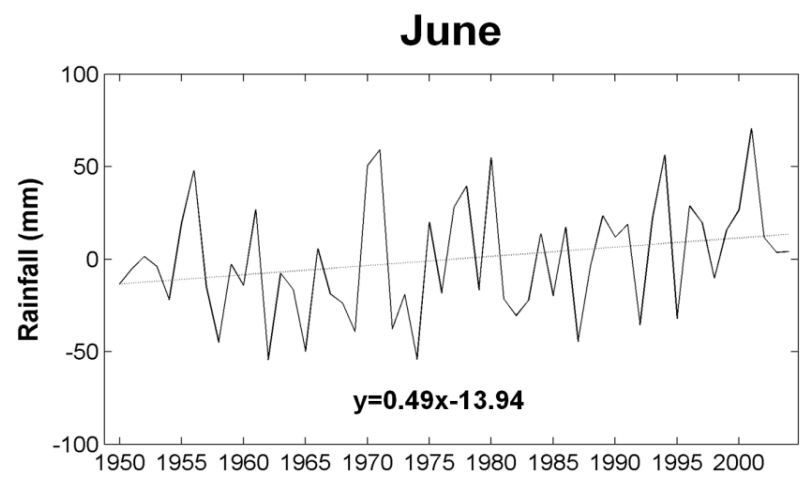

August

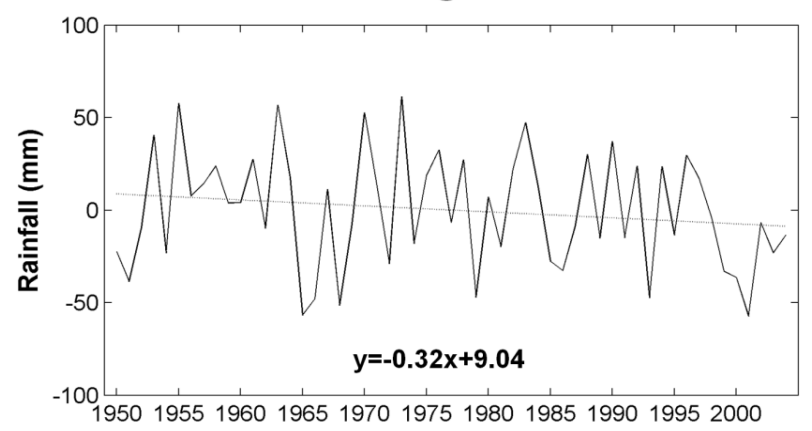

July

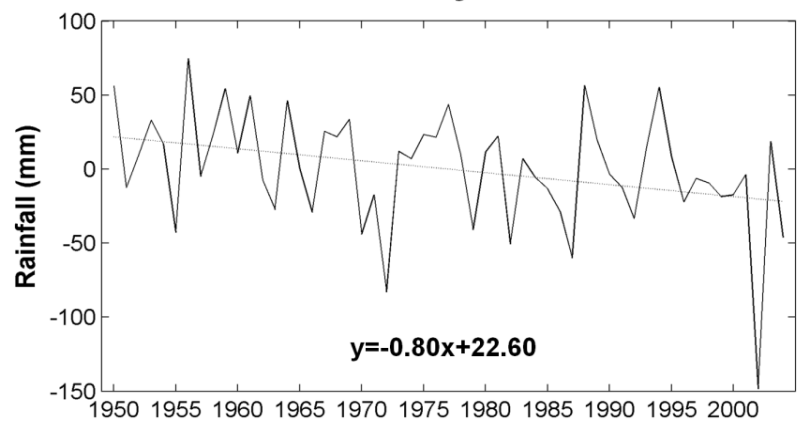

September

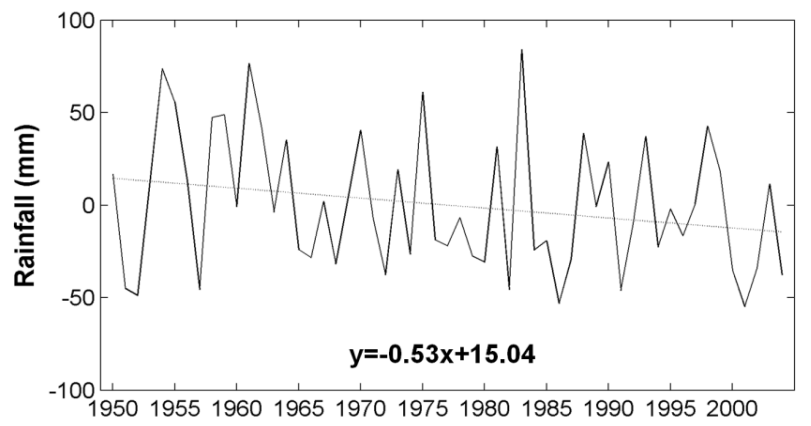

Fig. 7. Time series and linear trends of monthly separated All India Monsoon Rainfall for June, July, August and September from 1979 to 2004. June rainfall exhibits a characteristic increasing trend, while all remaining monsoon months show a significant weakening trend in recent past decades.
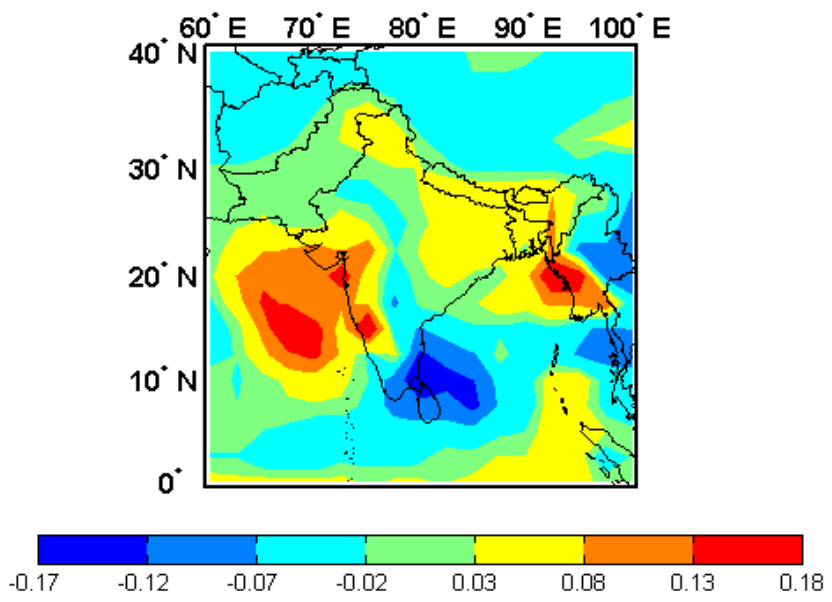

Fig. 8. Spatial trend analysis of June rainfall, from gauge and satellite measurements, indicates strong upward trends over the Indian Monsoon region including the Arabian Sea and the Bay of Bengal from 1979 to 2007 (Units: mm/day/year).

and other important forcing including the El Nino Southern Oscillation (Kumar et al., 1999).

\section{Summary}

With the growing attention on the potential effects of aerosol radiative forcing on the Indian monsoon rainfall and circulation in recent years (Menon et al., 2002; Ramanathan et al., 2005; Lau et al., 2006; Meehl et al., 2008), here we analyze the monsoon rainfall variability from long-term observations over India. In the context of rising global surface and tropospheric temperatures likely inducing changes in the Earth's hydrological cycle (Allen and Ingram, 2002; Held and Soden, 2006; Wentz et al., 2007) and in spite of the increasing trend of heavy rainfall events over India; albeit, the summer monsoon rainfall has been relatively stable in the past century (Goswami et al., 2006). Here we show that the early summer monsoon rainfall over India has significantly strengthened since 1950 s as indicated by historical rainfall data. The steady increase in rainfall could be led by enhanced pre-monsoon tropospheric warming observed over the Himalayas and the subsequent strengthening of the land-sea thermal gradient as indicated in the longest available record of microwave satellite measurements of tropospheric temperatures from 1979-2007 (Gautam et al., 2009b). The land-sea thermal gradient is one of the most important forcing in the Indian monsoon region which drives the circulation pattern from the equatorial Indian Ocean to the South 
Asian landmass. Although it is difficult to predict future composite JJAS rainfall trends (Goswami et al., 2006), however, our findings raise the intriguing possibility that if the tropospheric temperature trends continue, then in the coming years, the South Asian region could experience a wetter monsoon in early summer followed by a drier period. Our findings also have important bearings on agricultural practices and crop productivity which is vital to the South Asian socio-economic infrastructure.

It is thus imperative to monitor aerosols both over the source as well as sink regions in the monsoon dominated regions, especially when the role of aerosols on the hydrological cycle is being widely recognized in recent years with number of modeling efforts dedicated to this subject (Menon et al., 2002; Miller et al., 2004; Ramanathan et al., 2005; Lau et al., 2006; Meehl et al., 2008; Collier and Zhang, 2009). The observational results of monsoon rainfall variability in recent decades as presented in this paper complement the modeling results of Lau et al. (2006). However, reliable and more accurate information of the absorbing nature of aerosols is needed, particularly, of the pre-monsoon aerosols of which dust is a major component. Quantitative measurements of aerosol single scattering albedo is crucial in understanding the associated tropospheric warming and surface dimming; and thus their ramifications on the monsoon circulation and rainfall variability. Sophisticated ground-based measurements of aerosols, clouds and trace gases together with satellite A-Train series observations over the Asian monsoon regions as coordinated under the Joint Aerosol Monsoon Experiment (JAMEX) (Lau et al., 2008) framework would specifically provide detailed information about aerosol optical and radiative properties and will help reduce uncertainties associated with aerosol radiative forcing. Accurate information of aerosol absorption, incorporated into general circulation models, is required for reliable projections of aerosol forcing in order to examine their net response on tropospheric temperatures.

Acknowledgements. This work is supported by NASA Interdisciplinary Investigation Program, managed by Hal Maring. We also acknowledge support by the NASA Grant: NNX06AF30G - Global Environmental Change-hazards and regional impacts, and support by the technical officers Don Anderson and Lucia Tsaoussi. GOCART model outputs were obtained from the Giovanni web portal. We are grateful to the anonymous reviewers and the Editor for their constructive comments.

Topical Editor F. D'Andrea thanks three anonymous referees for their help in evaluating this paper.

\section{References}

Ahmad, S. P., Torres, O., Bhartia, P. K., Leptoukh, G., and Kempler, S. J.: Aerosol Index from TOMS and OMI Measurements, Proc. of the 86th AMS Annual Meeting, February 2006.

Allen, M. R. and Ingram, W. J.: Constraints on future changes in climate and the hydrological cycle, Nature, 419, 224-232, 2002.
Bollasina, M., Nigam, S., and Lau, K.-M.: Absorbing aerosols and summer monsoon evolution over South Asia: An observational portrayal, J. Climate, 21, 3221-3239, 2008.

Collier, J. C. and Zhang, G. J.: Aerosol direct forcing of the summer Indian monsoon as simulated by the NCAR CAM3, Clim. Dynam., 32, 313-332, doi:10.1007/s00382-008-0464-9, 2009.

Dash, S. K., Kulkarni, M. A., Mohanty, U. C., and Prasad, K.: Changes in the characteristics of rain events in India, J. Geophys. Res., 114, D10109, doi:10.1029/2008JD010572, 2009.

Dey, S., Tripathi, S. N., Singh, R. P., and Holben, B. N.: Influence of dust storms on the aerosol optical properties over the Indo-Gangetic plains, J. Geophys. Res., 109, D20211, doi:10.1029/2004JD004924, 2004.

El-Askary, H., Gautam, R., Singh, R. P., and Kafatos, M.: Dust Storms Detection over the Indo-Gangetic Plains using Multi Sensor Data, Adv. Space Res., 37, 728-733, 2006.

Fu, Q., Johanson, C. M., Warren, S. G., and Seidel, D. J.: Contribution of stratospheric cooling to satellite-inferred tropospheric temperature trends, Nature, 429, 55-58, 2004.

Gautam, R., Hsu, N. C., Kafatos, M., and Tsay, S.-C.: Influences of winter haze on fog/low cloud over the Indo-Gangetic plains, J. Geophys. Res., 112, D05207, doi:10.1029/2005JD007036, 2007.

Gautam, R., Liu, Z., Singh, R. P., and Hsu, N. C.: Two contrasting dust-dominant periods over India observed from MODIS and CALIPSO data, Geophys. Res. Lett., 36, L06813, doi:10.1029/2008GL036967, 2009.

Gautam, R., Hsu, N. C., Lau, K.-M., Tsay, S.-C., and Kafatos, M.: Enhanced pre-monsoon warming over the Himalayan-Gangetic region from 1979 to 2007, Geophys. Res. Lett., 36, L07704, doi:10.1029/2009GL037641, 2009.

Girolamo, L., Bond, T. C., Bramer, D., Diner, D. J., Fettinger, F., Kahn, R. A., Martonchik, J. V., Ramana, M. V., Ramanathan, V., and Rasch, P. J.: Analysis of Multiangle Imaging SpectroRadiometer (MISR) aerosol optical depths over greater India during winter 2001-2004, Geophys. Res. Lett., 31, L23115, doi:10.1029/2004GL021273, 2004.

Goes, J. I., Thoppil, P. G., Gomes, H. do R., and Fasullo, J. T.: Warming of the Eurasian landmass is making the Arabian Sea more productive, Science, 308, 545-547, 2005.

Goswami B. N., Venugopal, V., Sengupta, D., Madhusoodanan, M. S., and Xavier, P. K.: Increasing trend of Extreme Rain Events over India in a Warming Environment, Science, 314, 1442-1445, 2006.

Guttikunda, S. K., Carmichael, G. R., Calori, G., Eck, C., and Woo, J. H.: The contribution of mega cities to regional sulfur pollution in Asia, Atmos. Environ., 37, 11-22, 2003.

Habib, G., Venkataraman, C., Chiapello, I., Ramachandran, S., Boucher, O., and Reddy, M. S.: Seasonal and interannual variability in absorbing aerosols over India derived from TOMS: Relationship to regional meteorology and emissions, Atmos. Environ., 40, 1909-1921, 2006.

Held, I. M. and Soden, B. J.: Robust responses of the hydrological cycle to global warming, J. Climate, 19, 5686-5699, 2006.

Herman, J. R., Bhartia, P. K., Torres, O., Hsu, C., Seftor, C., and Celarier, E.: Global distribution of UV-absorbing aerosols from Nimbus 7/TOMS data, J. Geophys. Res., 102, 16911-19922, 1997.

Hsu, N., Herman, J., Bhartia, P., Seftor, C., Torres, O., Thompson, A., Gleason, J., Eck, T., and Holben, B.: Detection of 
Biomass Burning Smoke from TOMS Measurements, Geophys. Res. Lett., 23, 745-748, 1996.

Hsu, N. C., Herman, J. R., Torres, O., Holben, B. N., Tanre, D., Eck, T. F., Smirnov, A., Chatenet, B., and Lavenu, F.: Comparisons of the TOMS aerosol index with Sun-photometer aerosol optical thickness: Results and applications, J. Geophys. Res., 104(D6), 6269-6279, 1999.

Hsu, N. C., Tsay, S. C., King, M. D., and Herman, J. R.: Aerosol properties over bright-reflecting source regions, IEEE Trans. Geosci. Remote Sens., 42, 557-569, 2004.

Hsu, N. C., Tsay, S. C., King, M. D., and Herman, J. R.: Deep blue retrievals of Asian aerosol properties during ACE-Asia, IEEE Trans. Geosci. Remote Sens., 44, 3180-3195, 2006.

Huebert, B. J., Bates, T., Russell, P. B., Shi, G., Kim, Y. J., Kawamura, K., Carmichael, G., and Nakajima, T.: An overview of ACE-Asia: Strategies for quantifying the relationships between Asian aerosols and their climatic impacts, J. Geophys. Res., 108(D23), 8633, doi:10.1029/2003JD003550, 2003.

Jethva, H., Satheesh, S. K., and Srinivasan, J.: Seasonal variability of aerosols over the Indo-Gangetic plains, J. Geophys. Res., 110, D21204, doi:10.1029/2005JD005938, 2005.

Kaufman, Y. J. and Fraser, R. S.: The effect of smoke particles on clouds and climate forcing, Science, 277, 1636-1639, 1997.

Krishna Moorthy, K., Niranjan, K., Narasimhamurthy, B., Agashe, V. V., and Krishna Murthy, B. V.: ISRO-GBP Scientific Report, 03 99, 1999.

Kumar, K. K., Rajagopalan, B., and Cane, M. A.: On the weakening relationship between the Indian monsoon and ENSO, Science, 284, 2156-2159, 1999.

Lau, K. M., Kim, M. K., and Kim, K. M.: Asian monsoon anomalies induced by aerosol direct effects, Clim. Dynam., 26, 855864, doi:10.1007/s00382-006-0114-z, 2006a.

Lau K.-M. and Kim, K.-M.: Observational relationships between aerosol and Asian monsoon rainfall, and circulation, Geophys. Res. Lett., 33, L21810, doi:10.1029/2006GL027546, 2006 b.

Lau, K.-M., Kim, K.-M., Hsu, N. C., and Singh, R. P.: Seasonal covariability of aerosol and precipitation over the Indian monsoon and adjacent deserts, GEWEX News, 18(1), 4-6, 2008.

Lau, K. M., Ramanathan, V., Wu, G.-X., Li, Z., Tsay, S. C., Hsu, C., Siika, R., Holben, B., Lu, D., Tartari, G., Chin, M., Koudelova, P., Chen, H., Ma, Y., Huang, J., Taniguchi, K., and Zhang, R.: the Joint Aerosol-Monsoon Experiment: A New Challenge in Monsoon Climate Research, B. Am. Meteorol. Soc., 89, 369383, doi:10.1175/BAMS-89-3-369, 2008.

Levy, R. C., Remer, L. A., Mattoo, S., Vermote, E. F., and Kaufman, Y. J.: Second generation operational algorithm: Retrieval of aerosol properties over land from inversion of Moderate Resolution Imaging Spectroradiometer spectral reflectance, J. Geophys. Res., 112, D13211, doi:10.1029/2006JD007811, 2007.

Li, Z., Xia, X., Cribb, M., Mi, W., Holben, B., Wang, P., Chen, H., Tsay, S.-C., Eck, T. F., Zhao, F., Dutton, E. G., and Dickerson, R. R.: Aerosol optical properties and their radiative effects in northern China, J. Geophys. Res., 112, D22S07, doi:10.1029/2006JD007382, 2007.

Li, J., Carlson, B. E., and Lacis, A. A.: A study on the temporal and spatial variability of absorbing aerosols using Total Ozone Mapping Spectrometer and Ozone Monitoring Instrument Aerosol Index data, J. Geophys. Res., 114, D09213, doi:10.1029/2008JD011278, 2009.
Liu, Z., Liu, D., Huang, J., et al.: Airborne dust distributions over the Tibetan Plateau and surrounding areas derived from the first year of CALIPSO lidar observations, Atmos. Chem. Phys., 8, 5045-5060, 2008, http://www.atmos-chem-phys.net/8/5045/2008/.

Massie, S. T., Torres, O., and Smith, S. J.: Total Ozone Mapping Spectrometer (TOMS) observations of increases in Asian aerosol in winter from 1979 to 2000, J. Geophys. Res., 109, D18211, doi:10.1029/2004JD004620, 2004.

Meehl, G. A. and Arblaster, J. M.: Mechanisms for projected future changes in south Asian monsoon precipitation, Clim. Dynam., 21, 659-675, 2003.

Meehl, G. A., Arblaster, J. M., and Collins, W. D.: Effects of black carbon aerosols on the Indian monsoon, J. Climate, 21, 28692882, 2008.

Menon, S., Hansen, J., Nazarenko, L., and Luo, Y.: Climate effects of black carbon aerosols in China and India, Science, 297, 22502253, 2002.

Middleton, N. J.: A geography of dust storms in southwest Asia, Int. J. Clim., 6, 183-196, 1986.

Miller, R. L., Tegen, I., and Perlwitz, J.: Surface radiative forcing by soil dust aerosols and the hydrologic cycle, J. Geophys. Res., 109, D04203, doi:10.1029/2003JD004085, 2004.

Pandithurai, G., Dipu, S., Dani, K. K., Tiwari, S., Bisht, D. S., Devara, P. C. S., and Pinker, R. T.: Aerosol radiative forcing during dust events over New Delhi, India, J. Geophys. Res., 113, D13209, doi:10.1029/2008JD009804, 2008.

Parthasarathy, B., Munot, A. A., and Kothawale, D. R.: Monthly and seasonal rainfall series for all-India homogeneous regions and meteorological subdivisions: 1871-1994, Research Report No. RR-065, Indian Institute of Tropical Meteorology, Pune, 113 pp, 1995.

Prasad, A. K. and Singh, R. P.: Changes in aerosol parameters during major dust storm events (2001-2005) over the Indo-Gangetic Plains using AERONET and MODIS data, J. Geophys. Res., 112, D09208, doi:10.1029/2006JD007778, 2007.

Prospero, J. M., Ginoux, P., Torres, O., Nicholson, S. E., and Gill, T. E.: Environmental characterization of global sources of atmospheric soil dust identified with the Nimbus 7 Total ozone Mapping Spectrometer (TOMS) absorbing aerosol product, Rev. Geophys., 40, 1002, doi:10.1029/2000RG000095, 2002.

Ramanathan, V., Chung, C., Kim, D., Bettge, T., Buja, L., Kiehl, J. T., Washington, W. M., Fu, Q., Sikka, D. R., and Wild, M.: Atmospheric brown clouds: Impacts on South Asian climate and hydrological cycle, Proc. Natl. Acad. Sci. USA, 102, 5326-5333, 2005.

Rosenfeld, D., Rudich, Y., and Lahav, R.: Desert dust suppressing precipitation: A possible desertification feedback loop, Proc. Natl. Acad. Sci. USA, 98, 5975-5980, 2001.

Satheesh, S. K. and Ramanathan, V.: Large differences in tropical aerosol forcing at the top of the atmosphere and Earth's surface, Nature, 405, 60-63, 2000.

Sikka, D. R.: Developments in tropospheric aerosol studies in India, Ind. J. Radio Space Phys., 31, 391-403, 2002.

Sikka, D. R.: Evaluation of monitoring and forecasting of summer monsoon over India and a review of monsoon drought of 2002, Proc. Indian Natl. Sci. Acad., Part A, 69, 479-504, 2003.

Singh, R. P., Dey, S., Tripathi, S. N., Tare, V., and Holben, B.: Variability of aerosol parameters over Kanpur, northern India, J. 
Geophys. Res., 109, D23206, doi:10.1029/2004JD004966, 2004.

Singh, S., Nath, S., Kohli, R., and Singh, R.: Aerosols over Delhi during pre-monsoon months: Characteristics and effects on surface radiation forcing, Geophys. Res. Lett., 32, L13808, doi:10.1029/2005GL023062, 2005.

Shukla, J.: Interannual variability of monsoons, in: Monsoons, edited by: Fein, J. S. and Stephens, P. L., John Wiley \& Sons, New York, pp. 399-463, 1987.

Thompson, L. G., Yao, T., Mosley-Thompson, E., David, M. E., Henderson, K. A., and Lin, P.-N.: A high-resolution millennial record of the South Asian monsoon from Himalaya ice cores, Science, 289, 1916-1919, 2000.

Wellemeyer, C. G., Bhartia, P. K., Taylor, S. L., Qin, W., and Ahn, C.: Version 8 Total Ozone Mapping Spectrometer (TOMS) algorithm, presented at the 20th Quad. Ozone Symp., edited by: Zerefos, C. S., Athens, Greece, 2004.
Wentz, F. J., Ricciardulli, L., Hilburn, K., and Mears, C.: How much more rain will global warming bring?, Science, 317, 233-235, 2007.

Winker, D. M., Pelon, J., and McCormick, M. P.: The CALIPSO mission: Spaceborne lidar for observation of aerosols and clouds, Proc. SPIE Int. Soc. Opt. Eng., 4893, 1-11, 2003.

Xuan, J. and Sokolik, I. N.: Characterization of sources and emission rates of mineral dust in northern China, Atmos. Environ., 36, 4863-4876, 2002. 